Fourth International Conference on Sustainable Construction Materials and Technologies http://www.claisse.info/Proceedings.htm

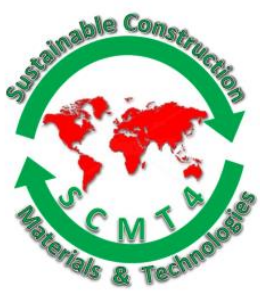

SCMT4

Las Vegas, USA, August 7-11, 2016

\title{
Bond Splitting Strength of 5-Year Field-Exposed Recycled Aggregate Concrete Beams with Melt-Solidified Slag Aggregate
}

\author{
Noritaka Morohashi ${ }^{1}$ \\ 1Department of Architecture and Architectural Engineering, College of Industrial Technology, \\ Nihon University, 1-2-1 Izumicho, Narashino-shi Chiba, 275-8575 Japan, Dr.Eng., \\ Email: <morohashi.noritaka@nihon-u.ac.jp>.
}

\begin{abstract}
This study discusses effective use of melt-solidified slag aggregate generated through the melting of domestic waste in a high-temperature melting zone between $1,700^{\circ} \mathrm{C}$ and $1,800^{\circ} \mathrm{C}$. Such melt-solidified slag aggregate was used as a substitute for natural fine aggregate at different substitution rates to suppress the drying shrinkage of recycled aggregate concrete (RAC). Beams of this RAC were kept exposed to field environments up to the material age of five years after concrete casting, and then subjected to structural testing. As a result, these 5-year field-exposed beams showed almost the same bond splitting strength regardless of the substitution rate, and their values were higher than those obtained in the tests at one year and two years. These results suggest that the 5-year field-exposed RAC beams have a sound internal concrete structure and good bond properties although they suffer minute cracks on the beam surfaces due to field exposure.
\end{abstract}

\section{INTRODUCTION}

This study discusses effective use of melt-solidified slag aggregate generated through the melting of domestic waste in a high-temperature melting zone between $1,700^{\circ} \mathrm{C}$ and $1,800^{\circ} \mathrm{C}$. Such melt-solidified slag aggregate [JIS A 5031] was used as a substitute for normal fine aggregate (natural sand) in combination with recycled aggregate to prepare recycled aggregate concrete (RAC). The recycled aggregate used originated from concrete debris generated as industrial waste in the process of demolishing reinforced concrete structures. In Japan, although RAC is already standardized in the Japanese Industrial Standard (JIS) [JIS A 5021, 5022, 5023], RAC using medium- or lower-quality recycled aggregate, which is relatively easy to produce, is likely to show higher drying shrinkage due to high water absorption of recycled aggregate. For this reason, the use of RAC is not yet popular in the country. In this study, melt-solidified slag aggregate with lower water absorption was used as fine aggregate for RAC to suppress drying shrinkage [Morohashi et al. 2013]. To determine the effect of the use of normal fine aggregate in combination with melt-solidified slag aggregate on bond properties, four specimen series were prepared with different substitution rates of slag aggregate for normal fine aggregate in this study. Also, to determine durability of RAC beams containing melt-solidified slag aggregate, specimens were exposed to the field after concrete casting and subjected to a loading testing at the material age of five years to check their bond properties [Morohashi et al. 2012, 2015]. This paper reports all of these 5-year field-exposed beams since their 
structural test has just been fully completed. Furthermore, for comparison of any difference due to the difference in curing condition, a comparison of bond splitting strength was made against specimens stored indoors up to the material age of five weeks, one year and two years, to determine the effect of drying shrinkage cracks seen in field-exposed beams due to exposure to wind, rain and direct sunlight on the bond splitting strength.

\section{TEST OUTLINE}

Table 1 shows the details of specimens and Table 2 the mix proportion of concrete. As basic research to determine the bond properties of RAC, $50 \%$ of normal coarse aggregate (crushed stone) was replaced by recycled medium-quality coarse aggregate. For fine aggregate, the rate of substitution of melt-solidified slag aggregate for normal fine aggregate (natural sand) (hereinafter referred to as "substitution rate") was changed for each set of specimens as in $25 \%, 50 \%, 75 \%$ and $100 \%$, in order to determine the effect of substitution rate on the bond splitting strength of RAC beams with melt-solidified slag aggregate. Four specimens were prepared for each series: a specimen for each of the experimental ages of five weeks, one year, two years and five years. Further, to determine the difference in bond splitting strength according to aging conditions, the test results for 5-year field-exposed beams were compared against those of another group of specimens stored in a laboratory building at the material ages of five weeks, one year and two years, respectively. The melt-solidified slag aggregate used in this study was manufactured in an integrated gasification high-temperature direct melting furnace at the Shibazono Cleaning Plant of Narashino City, Chiba Prefecture. The slag aggregate had a water absorption rate of $0.96 \%$ (for RM25S, RM75S series) and $0.38 \%$ (for RM50S, RM100S series), which were lower than normal fine aggregate (natural sand). In discussing the bond splitting strength, the test results for these specimens were compared against those for beams with no melt-solidified slag aggregate at the material age of two years as well.

Table 1. Details of specimens

\begin{tabular}{|c|c|c|}
\hline Specimens & $\begin{array}{c}\text { Series } \\
\text { The rate of substitution }\end{array}$ & $\begin{array}{l}\text { Experiment } \\
\text { age }\end{array}$ \\
\hline 1)RM0S & \multirow{3}{*}{$\begin{array}{c}\text { RM0S series: } \\
\text { Normal fine aggregate }(100 \%)\end{array}$} & 5 weeks \\
\hline 2)RM0S1K & & 1 year \\
\hline 3)RM0S2K & & 2 years \\
\hline 4)RM25S & \multirow{4}{*}{$\begin{array}{c}\text { RM25S series: } \\
\text { Normal fine aggregate }(75 \%) \\
\text { Melt-solidified } \\
\text { slag aggregate }(25 \%)\end{array}$} & 5 weeks \\
\hline 5)RM25S1K & & 1 year \\
\hline 6)RM25S2K & & 2 years \\
\hline 7)RM2 & & 5 years \\
\hline 8)RM50S & \multirow{4}{*}{$\begin{array}{c}\text { RM50S series: } \\
\text { Normal fine aggregate }(50 \%) \\
\text { Melt-solidified } \\
\text { slag aggregate }(50 \%)\end{array}$} & 5 weeks \\
\hline 9)RM50S1K & & 1 year \\
\hline 10)RM50S2K & & 2 years \\
\hline 11)RM50S5E & & 5 years \\
\hline 12) $\mathrm{RM} 75 \mathrm{~S}$ & \multirow{4}{*}{$\begin{array}{c}\text { RM75S series: } \\
\text { Normal fine aggregate }(25 \%) \\
\text { Melt-solidified } \\
\text { slag aggregate }(75 \%)\end{array}$} & 5 weeks \\
\hline 13)RM75S1K & & 1 year \\
\hline 14)RM75S2K & & 2 years \\
\hline 15)RM75S5E & & 5 years \\
\hline 16)RM100S & \multirow{4}{*}{$\begin{array}{c}\text { RM100S series: } \\
\text { Melt-solidified } \\
\text { slag aggregate }(100 \%)\end{array}$} & 5 weeks \\
\hline 17)RM100S1K & & 1 year \\
\hline 18)RM100S2K & & 2 years \\
\hline 19)RM100S5E & & 5 years \\
\hline
\end{tabular}

Length of lapped splice : $l \mathrm{~s}=30 \mathrm{~d}_{\mathrm{b}}=570(\mathrm{~mm}), \mathrm{b} \times \mathrm{D}=300 \times 300 \mathrm{~mm}$ 
Table 2. Mix proportion of concrete

\begin{tabular}{|l|c|c|c|c|c|c|c|}
\hline \multirow{2}{*}{ Series } & \multirow{2}{*}{$\begin{array}{c}\text { W/C } \\
(\%)\end{array}$} & & Water & Cement & \multicolumn{2}{|c|}{ Feight $\left(\mathrm{kg} / \mathrm{m}^{3}\right)$} \\
\cline { 3 - 8 } & & & & $\begin{array}{c}\text { Melt- } \\
\text { Normal } \\
\text { solidified } \\
\text { slag }\end{array}$ & Normal & Recycled \\
\hline RM0S & 65.0 & 180 & 277 & 816 & - & 503 & 455 \\
\hline RM25S & 65.0 & 184 & 283 & 653 & 238 & 473 & 424 \\
\hline RM50S & 72.5 & 184 & 254 & 448 & 490 & 473 & 424 \\
\hline RM75S & 65.0 & 184 & 283 & 218 & 713 & 473 & 424 \\
\hline RM100S & 69.4 & 184 & 265 & - & 968 & 473 & 424 \\
\hline
\end{tabular}

Figure 1 shows the shape of the specimens and Figure 2 their cross section. A lap splice of a length of 30 $\mathrm{d}_{\mathrm{b}}\left(\mathrm{d}_{\mathrm{b}}\right.$ : nominal diameter of main reinforcement) was installed to each specimen on the bottom surface of the pure bending section so as to determine the bond properties. 4-D19 (SD345) was used as top and bottom main reinforcing bars. The cover from the specimen surface on both sides and the bottom to the nearest end of the main reinforcing bars was $30 \mathrm{~mm}$. These beams were investigated for bond splitting strength assuming a side-split mode bond splitting failure.

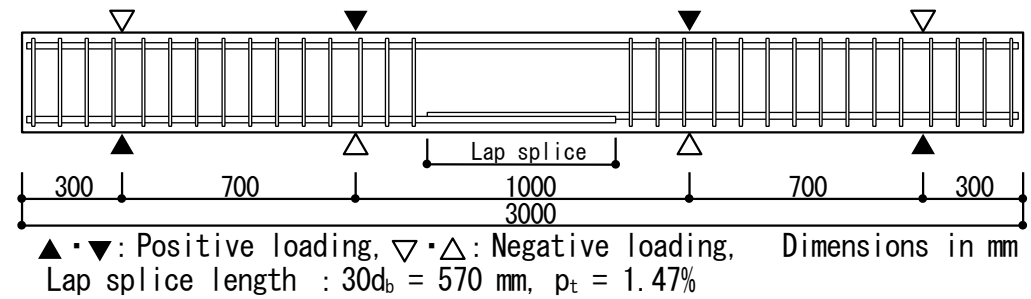

Figure 1. Shape of the specimens

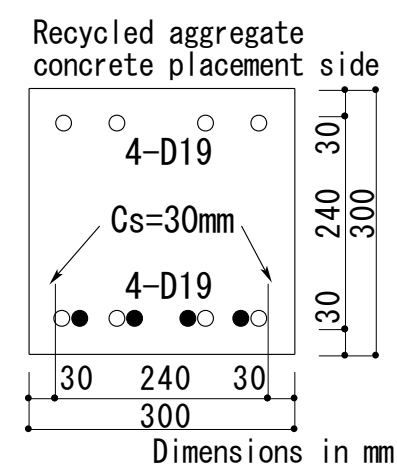

Figure 2. Cross section

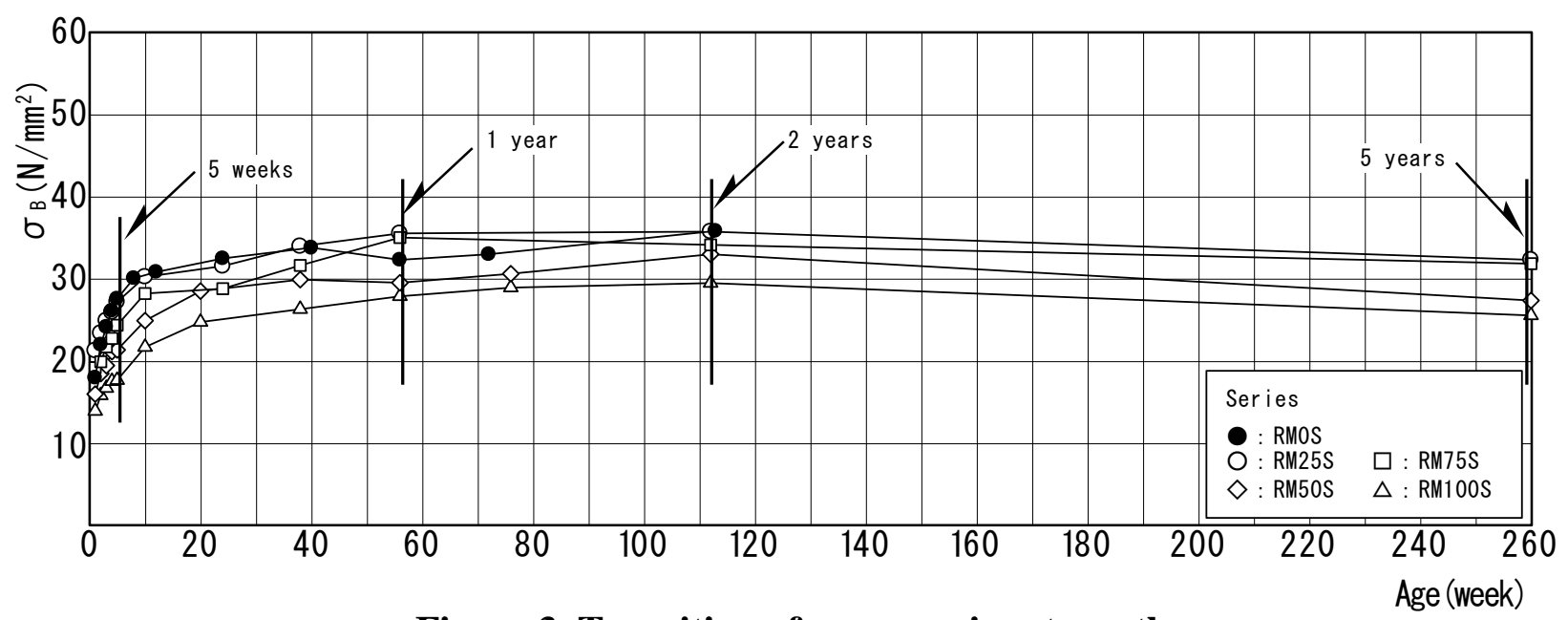

Figure 3. Transition of compressive strength 


\section{CONCRETE STRENGTH}

Figure 3 shows changes in compressive strength of the concrete beams with time up to the material age of five years. Sealed-cured cylindrical specimens (sealed with thick plastic sheets) were used for compressive strength measurement. For measurement of drying shrinkage, length change prismatic specimens of 100 $\mathrm{mm} \times 100 \mathrm{~mm} \times 400 \mathrm{~mm}$, which are used in the measurement for length change of concrete according to JIS A 1129 [JIS A 1129], were stored in a thermo-hygrostat (temperature $20^{\circ} \mathrm{C} \pm 2{ }^{\circ} \mathrm{C}$, humidity $60 \% \pm$ $5 \%$ ) before testing. The result showed that the compressive strengths obtained in tests at one year and at two years were higher than those in the test at five weeks although some variations were observed. However, the compressive strength in the test at five years was lower than that in the test at two years. This decrease in compressive strength was probably caused by drying shrinkage of the sealed-cured test pieces due to dissipation of contained water that occurred as the material age increased.

\section{DRYING SHRINKAGE RATE AND DRYING SHRINKAGE CRAKS}

Figure 4 shows changes in drying shrinkage of the concrete beams with material age. An increase in the drying shrinkage rate can be observed at five weeks, 26 weeks and 52 weeks (one year). After the test at one year, the shrinkage rate remains almost flat until the test at five years, only with a slight increase. RM25S (marked with a circle "॰") in which $25 \%$ of the normal fine aggregate (natural sand) was replaced by melt-solidified slag aggregate shows a drying shrinkage rate above $1,000 \times 10^{-6}$ in the test at five years. On the other hand, RM100S (marked with a triangle " $\Delta "$ ) in which $100 \%$ of the normal fine aggregate (natural sand) is replaced by melt-solidified slag aggregate only shows just over $600 \times 10^{-6}$ in the test at five years. Thus specimens with a high substitution rate show such a low drying shrinkage rate.

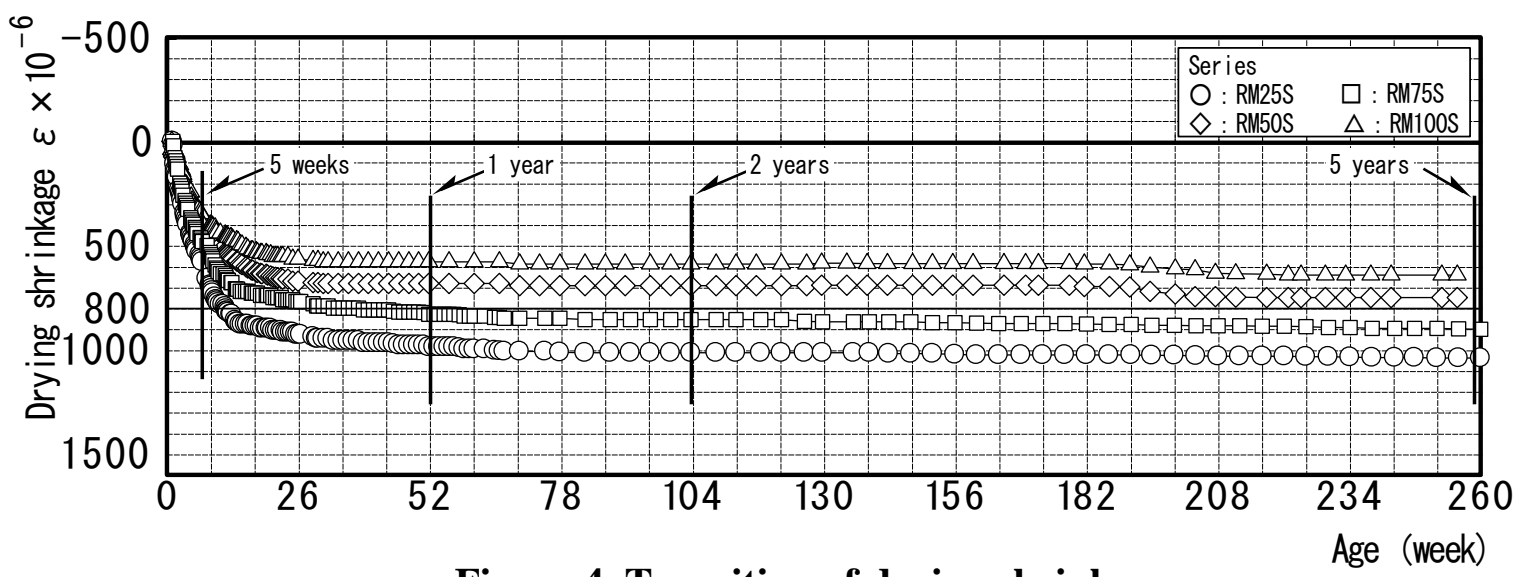

Figure 4. Transition of drying shrinkage

Figures 5 a) to d) give examples of how drying shrinkage cracks occurred in field-exposed beams (RM75S5E) on their south side at one year, two years, three years and five years. The field-exposed beams started to have drying shrinkage cracks at the material age of one year to two years, and suffered substantial drying shrinkage cracks for a material age between two years and three years. These cracks did not develop so much for a material age between three years and five years. When comparing drying shrinkage cracks among field-exposed beams with different substitution rates at the material age of five years, a number of minute cracks were found in all beams regardless of substitution rate. This was probably because these field-exposed beams were repeatedly exposed to dry and wet conditions such as wind, rain and direct sunlight. 


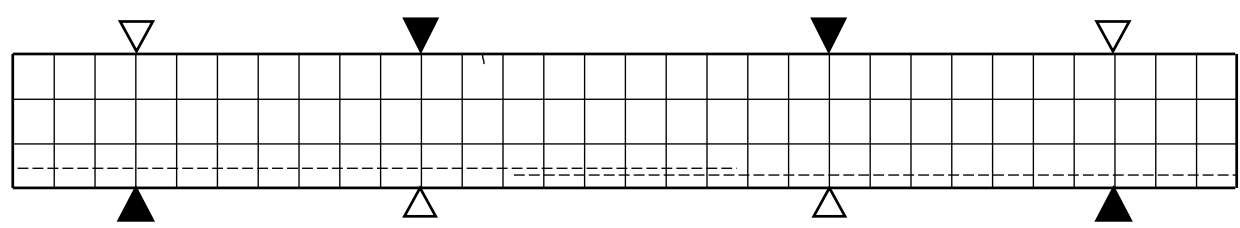

a) 1 year

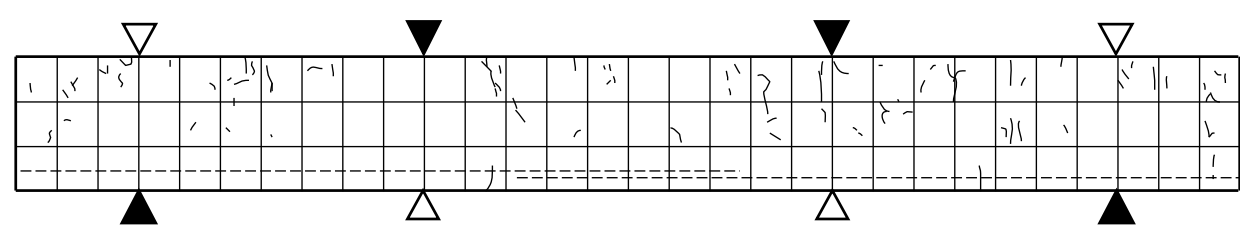

b) 2 years

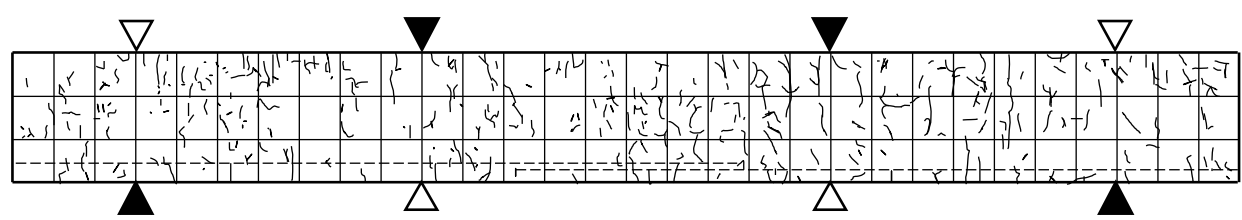

c) 3 years

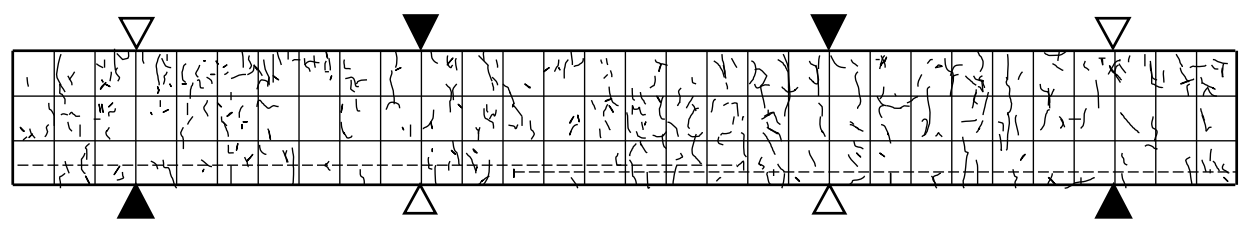

d) 5 years

Figure 5. Drying shrinkage cracks in field-exposed beams (RM75S5E)

\section{TEST RESULTS}

Table 3 summarizes the test results. In terms of failure pattern, all beams had a bond splitting failure prior to flexural yielding in the test at five weeks, and flexural yielding followed by a bond splitting failure at five years. In the tests at one year and two years, some beams had a bond splitting failure prior to flexural yielding, and some others had flexural yielding followed by a bond splitting failure.

\section{Final failure pattern}

Figures 6 a) to d) show the final failure pattern for RM75S beams over their total beam length at five weeks, one year, two years and five years. Figure 7 gives the final failure pattern for RM75S5E in their pure bending section at five years.

The cracks developing from the top surface represent the flexural cracks that occurred when a negative load was applied. When a positive load was applied, initial flexural cracks occurred in the pure bending section, and then flexural shear cracks occurred outside the pure bending section. As seen in the final failure pattern of the pure bending section in Figure 7, the beams finally had a side-split mode bond splitting failure in which horizontal cracks abruptly occurred in the longitudinal direction of the beam over the length of the lap splice when the maximum load was applied. No difference was observed between the final failure pattern of field-exposed beams subjected to load at five years, and that of the beams stored indoors up to five weeks, one year and two years. 
Table 3. Test results

\begin{tabular}{|l|c|c|c|c|}
\hline \multicolumn{1}{|c|}{ Specimens } & $\begin{array}{c}\sigma_{\mathrm{B}} \\
\left(\mathrm{N} / \mathrm{mm}^{2}\right)\end{array}$ & $\begin{array}{c}\mathrm{P}_{\max } \\
(\mathrm{kN})\end{array}$ & $\begin{array}{c}\tau_{\mathbf{u} \text { exp. }} \\
\left(\mathrm{N} / \mathrm{mm}^{2}\right)\end{array}$ & $\begin{array}{c}\text { Failure } \\
\text { mode }\end{array}$ \\
\hline 1)RM0S & 27.5 & 264.0 & 2.96 & $\mathrm{~S}$ \\
\hline 2)RM0S1K & 32.3 & 289.2 & 3.26 & $\mathrm{~S}$ \\
\hline 3)RM0S2K & 35.8 & 267.0 & 3.00 & $\mathrm{~S}$ \\
\hline 4)RM25S & 27.2 & 278.0 & 3.12 & $\mathrm{~S}$ \\
\hline 5)RM25S1K & 35.5 & 260.0 & 2.92 & $\mathrm{~S}$ \\
\hline 6)RM25S2K & 35.8 & 293.5 & $(3.29)$ & $\mathrm{FS}$ \\
\hline 7)RM25S5E & 32.3 & 290.0 & $(3.26)$ & $\mathrm{FS}$ \\
\hline 8)RM50S & 21.3 & 296.8 & 3.33 & $\mathrm{~S}$ \\
\hline 9)RM50S1K & 29.5 & 291.0 & $(3.27)$ & $\mathrm{FS}$ \\
\hline 10)RM50S2K & 33.0 & 286.0 & 3.21 & $\mathrm{~S}$ \\
\hline 11)RM50S5E & 30.8 & 298.5 & $(3.35)$ & $\mathrm{FS}$ \\
\hline 12) RM75S & 24.4 & 223.0 & 2.50 & $\mathrm{~S}$ \\
\hline 13)RM75S1K & 35.0 & 225.5 & 2.53 & $\mathrm{~S}$ \\
\hline 14)RM75S2K & 34.1 & 255.0 & 2.86 & $\mathrm{~S}$ \\
\hline 15)RM75S5E & 31.8 & 300.2 & $(3.37)$ & $\mathrm{FS}$ \\
\hline 16)RM100S & 17.7 & 199.2 & 2.24 & $\mathrm{~S}$ \\
\hline 17)RM100S1K & 27.9 & 235.5 & 2.64 & $\mathrm{~S}$ \\
\hline 18)RM100S2K & 29.5 & 250.5 & 2.81 & $\mathrm{~S}$ \\
\hline 19)RM100S5E & 29.1 & 315.5 & $(3.54)$ & $\mathrm{FS}$ \\
\hline
\end{tabular}

$\mathrm{S}$ :Bond splitting failure

FS:Bond splitting failure after flexural yielding

a) $\mathrm{RM75S} \operatorname{Pmax}=223.0 \mathrm{kN}$

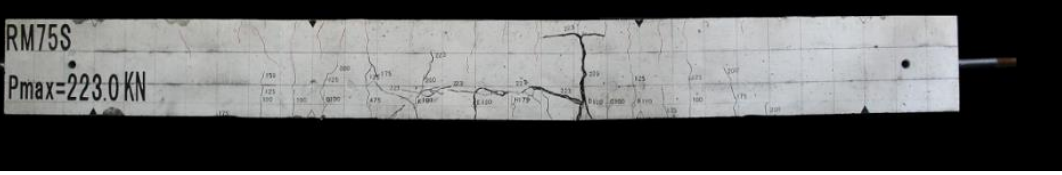

b) RM75S1K Pmax $=225.5 \mathrm{kN}$

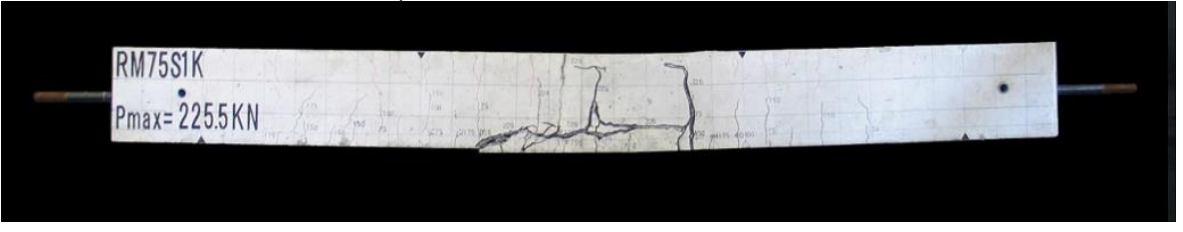

c) $\mathrm{RM75S2K} P \max =255.0 \mathrm{kN}$

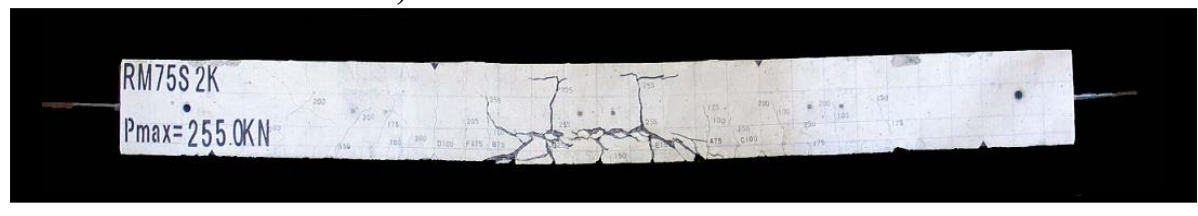

d) RM75S5E Pmax $=300.2 \mathrm{kN}$

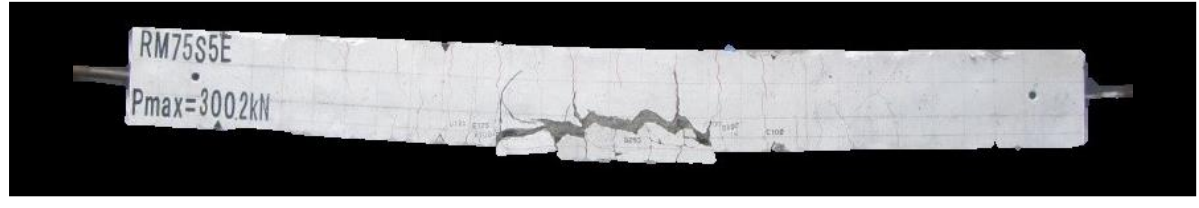

Figure 6. Final failure pattern for RM75S beams 


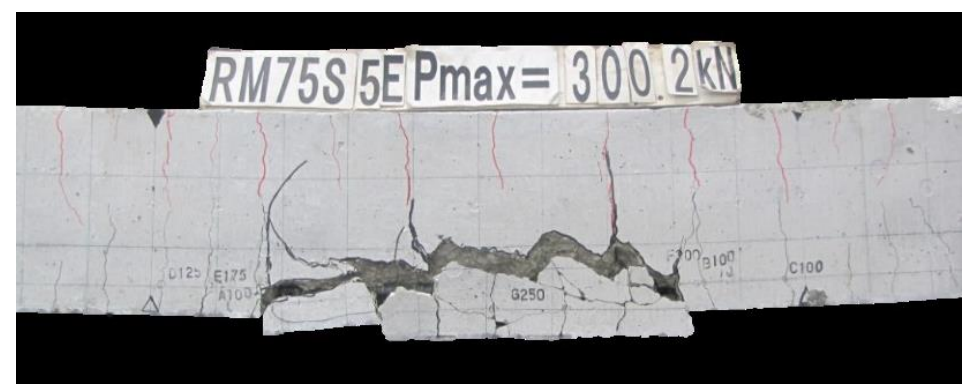

Figure 7. Final failure pattern for RM75S5E (Pure bending section)

Maximum flexural crack width under allowable unit stress for sustained loading. Figure 8 shows the maximum flexural crack width Wmax with the allowable unit stress for sustained loading on the main reinforcement. All specimen series showed a Wmax value that was lower than the upper limit target of 0.25 $\mathrm{mm}$ specified by the Standard for structural calculation of reinforced concrete structures [AIJ Standard 2010]. Among the beams stored indoors up to two years, the RM0S, RM25S and RM75S series showed a slight increase in maximum flexural crack width. Among 5-year field-exposed beams, the RM50S, RM75S and RM100S series showed a slight increase in maximum flexural crack width. It can be generally derived from these results that beams subjected to structural testing after aging tend to have a wider maximum flexural crack width under the allowable unit stress for sustained loading on the main reinforcement due to drying shrinkage cracks that occurred before loading.

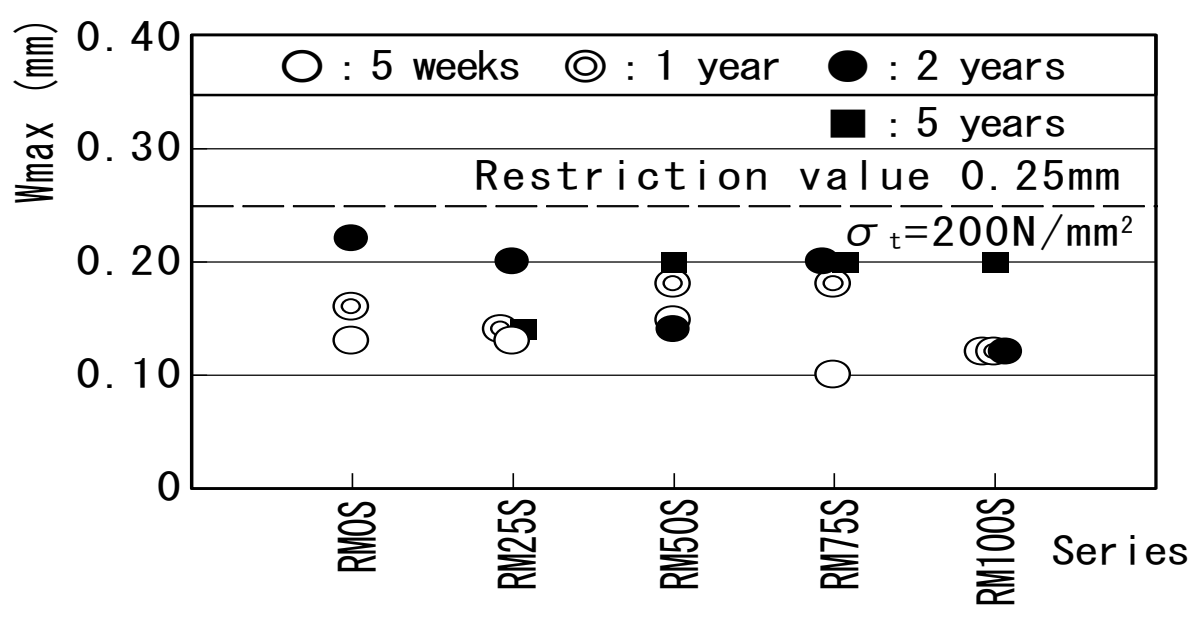

Figure 8. Maximum flexural crack width Wmax

Displacement characteristics. Figure 9 provides load-displacement curves for the RM75S series as an example. Two-point concentrated positive and negative loads were repeatedly applied. Cyclic positive and negative loading was performed once at each of the main reinforcement unit stress $\left(\sigma_{t}\right)$ levels: 100, 200, and $300 \mathrm{~N} / \mathrm{mm}^{2}$ (in increments of $100 \mathrm{~N} / \mathrm{mm}^{2}$ ). The RM75S series showed a bond splitting failure prior to flexural yielding in tests at five weeks, one year and two years. In the test at five years, they showed flexural yielding followed by a bond splitting failure. A trend can be found that flexural rigidity values against positive loading at one year, two years and five years are slightly lower than those at five weeks indicated by a broken line in the diagram, although it is not clearly identified due to several imposed curves. This was probably because drying shrinkage cracks developed after the test at five weeks, which reduced the rigidity. 


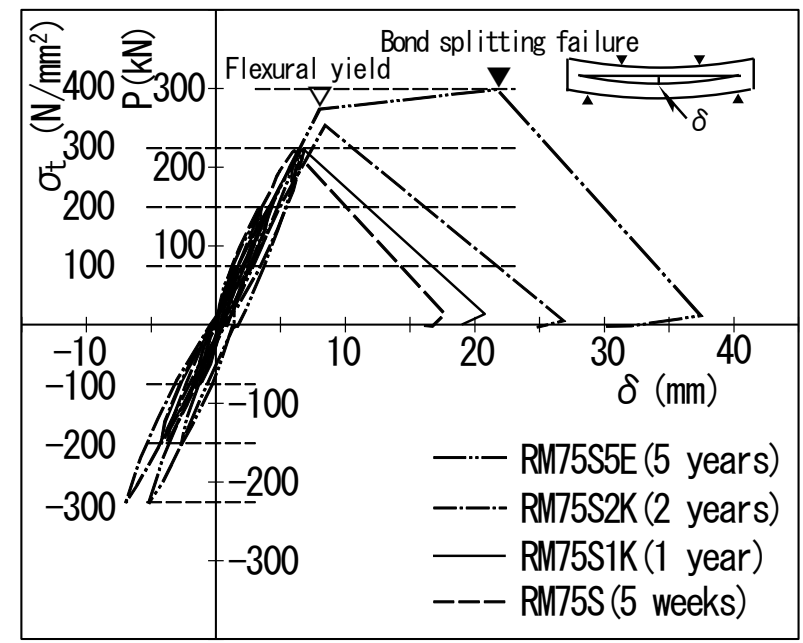

Figure 9. Load-displacement curves for the RM75S series

Evaluation of bond splitting strength. The bond splitting strength was calculated from equation (1) [JAMES G. MACGREGOR 1988]:

$$
\tau_{\text {u exp. }}=\frac{\mathrm{Mu}}{\mathrm{j} \cdot \psi \cdot l \mathrm{~s}} \quad\left(\mathrm{~N} / \mathrm{mm}^{2}\right)
$$

where, Mu: Maximum bending moment $(\mathrm{N} \cdot \mathrm{mm})$

j: (7/8)d (d: Effective beam depth $260.5 \mathrm{~mm})$

$\psi$ : Perimeter of reinforcement (4-D19 $240 \mathrm{~mm})$

$l \mathrm{~s}$ : Length of lap splice $\left(30 \mathrm{~d}_{\mathrm{b}} 570 \mathrm{~mm}\right)$

Figure 10 shows the bond splitting strength of each specimen series. For beams exposed to field for five years (marked with a square " $\square ")$, no difference in bond splitting strength was found among specimen series with different substitution rates from $25 \%$ to $100 \%$. However, their bond splitting strength was generally higher than the results at one year and two years. The beams with melt-solidified slag aggregate replacing normal fine aggregate (natural sand) showed a higher bond splitting strength than the result for beams with no melt-solidified slag aggregate (RMOS series) at two years. Particularly for those with a substitution rate of 75\% (RM75S series) and 100\% (RM100S series), the difference at two years and five years was obvious. These results imply that 5-year field-exposed RAC beams had a sound internal concrete structure and good bond properties although they suffered minute cracks on the beam surfaces due to field exposure.

\section{CONCLUSION}

The study on bond properties of 5-year field-exposed RAC beams with melt-solidified slag aggregate led to the following findings within the scope of the related tests:

1) The drying shrinkage rate of beams only slightly increased after the test at one year until the test at five years. The higher the substitution rate was (up to 100\%), the lower the drying shrinkage rate was.

2) A number of minute drying shrinkage cracks were found in field-exposed beams at the material age of five years regardless of substitution rate.

3) Both 5-year field-exposed beams and indoor-stored beams during load testing at two years showed a side-split mode bond splitting failure as the final failure pattern. 


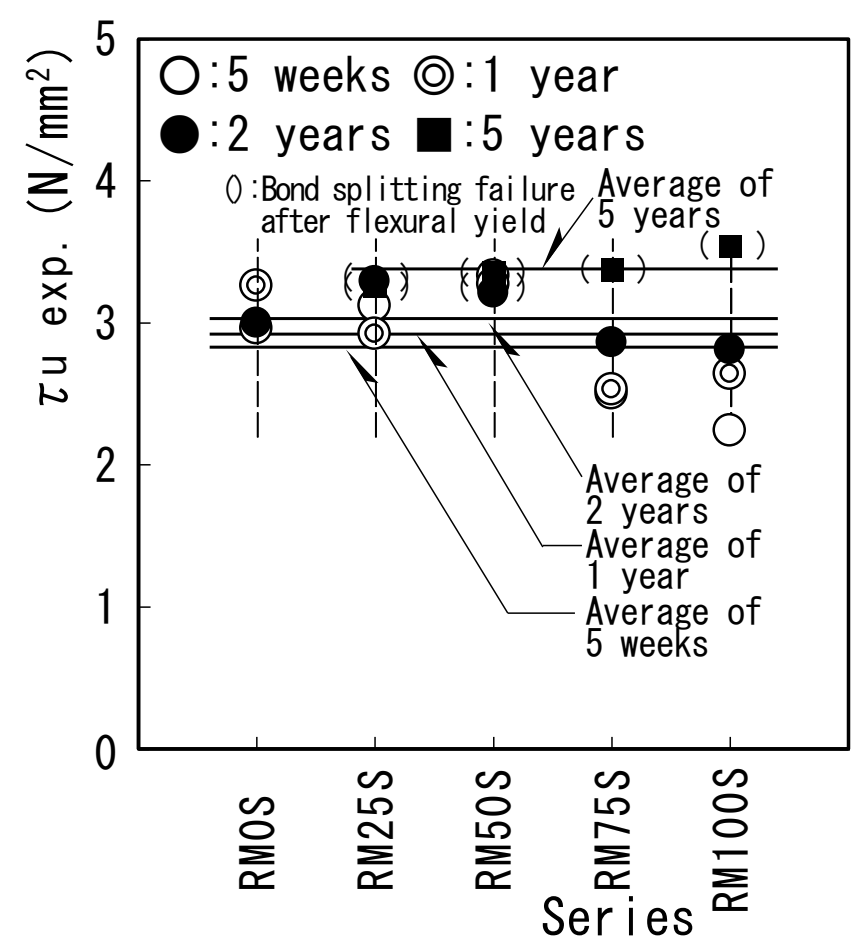

Figure 10. Bond splitting strength

4) Beams subjected to structural testing after aging tended to have a larger maximum flexural crack width under the allowable unit stress for sustained loading on the main reinforcement due to the effect of drying shrinkage cracks.

5) In general, the flexural rigidity to positive loading in tests at one year, two years and five years was slightly lower than that in the test at five weeks.

6) In general, the bond splitting strength of field-exposed beams measured in the test at five years was, regardless of the substitution rate, higher than that of indoor-stored beams at one year and two years.

As mentioned above, with the aim of suppressing drying shrinkage of RAC, melt-solidified slag aggregate was mixed in the concrete to measure the drying shrinkage and observe the occurrences of drying shrinkage cracks up to the material age of five years, and then structural testing was conducted. As a result, a trend was observed that field-exposed beams had a higher bond splitting strength than indoor-stored beams, although the former suffered a number of minute drying shrinkage cracks unlike the latter. In the future, we will make a comparison between calculated values according to the bond splitting strength equation and the experimental values.

\section{ACKNOWLEDGEMENT}

This study was conducted using an automatic measurement control system for a large research equipment structural testing machine under the jurisdiction of the Research Institute of Industrial Technology, Nihon University. Shibazono Cleaning Plant of Narashino City agreed quite readily to allow us to use their meltsolidified slag aggregate. Kasai Recycled Concrete Plant of the Tokyo Construction Waste Disposal Cooperative Association kindly provided us with recycled aggregate. A chemical admixture manufacturer "F" extended a great deal of cooperation with concrete mixing. We would like to express our deep gratitude to all those concerned. 


\section{REFERENCES}

AIJ Standard (2010)“AIJ Standard for Structural Calculation of Reinforced Concrete Structures revised 2010.” Architectural Institute of Japan

JAMES G. MACGREGOR(1988) “Reinforced Concrete Mechanics and Design”,Prentice Hall,p.93

Japanese Standards Association(2010).“JIS A 1129 Methods of measurement for length change of mortar and concrete -Part 2:Method with contact-type strain gauge"Revised 2010-08-10

Japanese Standards Association(2011).“JIS A 5021 Recycled aggregate for concrete-class H.”Revised 2011-05-20

Japanese Standards Association(2012).“JIS A 5022 Recycled concrete using recycled aggregate class M.’Revised 2012-07-20

Japanese Standards Association(2012).“JIS A 5023 Recycled concrete using recycled aggregate class L."Revised 2012-07-20

Japanese Standards Association(2010)."JIS A 5031 Melt-solidified slag aggregate for concrete derived from municipal solid waste and sewage sludge.”Revised 2010-07-20

Noritaka MOROHASHI , Tomoyuki SAKURADA and Hiromi MITSUHASHI(2013)."AN EXPERIMENTAL STUDY ON THE BOND PROPERTIES OF BEAMS USING MELT-SOLIDIFIED SLAG INSTEAD OF FINE AGGREGATE OF RECYCLED CONCRETE."JOURNAL OF STRUCTURAL ENGINEERING, Vol.57B, Architectural Institute of Japan, pp.665-672

Noritaka Morohashi and Tomoyuki Sakurada(2012)."Long-term Drying Shrinkage Properties for up to 2 Years of Beams with Medium-quality Recycled Coarse Aggregate in the Japanese Industrial Standards."International Concrete Sustainability Conference, (C) National Ready Mixed Concrete Association,pp.1-13

Noritaka Morohashi(2015)."BOND PROPERTIES OF FIELD-EXPOSED BEAMS WITH MEDIUMQUALITY RECYCLED COARSE AGGREGATE AND MELT-SOLIDIFIED SLAG AGGREGATE."Fifith International Concrete on Construction Materials: Performance, Innovations and Structural Implications, August 19-21 2015. Whistler, Canada,pp.695-704 